\title{
O SOM DO SILÊNCIO: VIBRAÇÕES DA MÚSICA NO DESENVOLVIMENTO SOCIOCULTURAL DA CRIANÇA COM ESPECTRO AUTISTA
}

\section{THE SOUND OF SILENCE: VIBRATIONS OF MUSIC IN THE SOCIOCULTURAL DEVELOPMENT OF THE CHILD WITH AUTISTIC SPECTRUM}

DOI: http://dx.doi.org/10.5965/1984317816012020149

Garbareth Edianne Mattos

Universidade Regional de Blumenau

garbarethma@gmail.com

Rita Buzzi Rausch

Universidade Regional de Blumenau rausch@furb.br

Amanda Lang

Universidade Regional de Blumenau lang.amandita@gmail.com

\begin{abstract}
RESUMO
Este artigo configura-se como uma análise da música no desenvolvimento sociocultural da criança com espectro autista, partindo das experiências e inquietações das pesquisadoras em relação a esta temática no contexto educativo da Educação Infantil. Possui como objetivo compreender as repercussões e vibrações da música no desenvolvimento sociocultural da criança com espectro autista na Educação Infantil e a partir disso, instigar reflexões sobre o tema. Trata-se de uma pesquisa qualitativa de cunho teórico, mas que também apresenta sugestões práticas de como regular o espaço com música para criança com espectro autista. Toma como percurso, sobretudo, as ideias de Vigotski $(1929,1995$, 1997, 1998, 2009, 2003, 2010). Por intermédio desse texto, suscita-se reflexões sobre os processos de apropriação da criança com espectro autista com os signos da música, e como a música pode potencializar ações educativas em relação à inclusão na Educação Infantil. Na produção deste artigo, desvela-se a importância de pensar em práticas educativas para crianças com espectro autista, enfatizando uma inclusão mais humanizadora, crítica e consciente por meio da educação musical.
\end{abstract}

Palavras-chave: Educação Infantil. Espectro Autista. Música. Inclusão.

\section{ABSTRACT}

This article is configured as an analysis of music in the sociocultural development of children with autistic spectrum based on the researchers' experiences and concerns regarding this theme in the educational context of early childhood education. It aims to understand the repercussions and vibrations of music on the socio-cultural development of children with autistic spectrum in early childhood education and from that instigate reflections on the subject. This is a qualitative research of theoretical nature, but it also presents practical suggestions on how to regulate the space with music for children with autism spectrum. It takes mainly ideas of Vigotski $(1929,1995,1997,1998,2009,2003,2010)$. Through this text it raises reflections on the processes of appropriation of children with autistic spectrum with the signs of music and how music can enhance educational actions regarding inclusion in early childhood education. In the production of this article the importance of thinking about educational practices for children with autistic spectrum is revealed emphasizing a more humanizing, critical and conscious inclusion through music education. 
Keywords: Autistic Spectrum. Child Education. Music. Inclusion.

\section{INTRODUÇÃO}

The Sound of Silence/ Simon e Garfunkel

And in the naked light I saw Ten thousand people, maybe more

People talking without speaking

People hearing without listening

People writing songs

That voices never share

And no one dare

Disturb the sound of silence

Fools, said I, you do not know

Silence like a cancer grows

Hear my words that I might teach you

Take my arms that I might reach to you

But my words like silent raindrops fell

And echoed in the wells of silence...

Com um trecho do texto da música "Sound of Silence" suscitamos pensar sobre o silêncio que permeia o espaço da Educação Infantil, entre outros, quando falamos sobre o espectro autista, pois, muitas vezes, não ousamos "perturbar o som do silêncio". Quando não observamos com acuidade que cada criança é singular, estamos fomentando que esse silêncio cresça. Precisamos escutar sua voz que é silenciada, não pela criança, mas pelo contexto da Educação Infantil que não compreende suas potencialidades, maneiras de ver e sentir o mundo que a permeia.

Por isso, neste artigo, temos como intento instigar reflexões teóricas e compartilhar experiências, inquietações, questionamentos sobre o tema do desenvolvimento sociocultural da criança com espectro autista por meio da música. Tomamos a música como fio condutor, pois queremos pensar nas possibilidades da música em espaços de acontecimentos, em um corpo que vibra, em movimentos que nos contemple pensar sobre e quem sabe transformar o nosso olhar enquanto professores. Com isso, perseguimos nesta investigação, a seguinte inquietação: Quais as principais repercussões/vibrações da música no desenvolvimento sociocultural da criança com autismo na Educação Infantil?

Pensar no outro implica o reconhecimento do diferente, nas singularidades e adversidades. É preciso reconhecer a possibilidade de mudança, de novos olhares, 
sem as barreiras e estigmas oriundos do preconceito. Nessa perspectiva, Dussel (2001, p. 70$)$ relata que:

Aceitar o argumento do outro se supõe o aceitar o outro como igual, e esta aceitação do outro como igual é uma posição ética, é o reconhecimento ético ao outro como igual, quer dizer, aceitar o argumento não é somente uma questão de verdade é também uma aceitação do outro.

Os impactos da segregação são visíveis nos tempos atuais. No contexto de ensino, durante nosso percurso enquanto professoras, lembramos de divisões sociais, essas que não se aplicavam à matemática, mas sim, ao processo de segregação, separações de indivíduo pela sua nota ou "capacidade intelectual mais aprimorada". Não existia, muitas vezes, um olhar sensível sobre os processos de aprender de cada ser humano. Ao longo do período de sua existência, a escola, durante anos, foi lugar dos "invisíveis", permitindo que desaparece uma parcela de estudantes do cenário escolar. E nesse sentido, trazemos a tirinha do Armandinho1 (figura 1) como justificativa, em relação à empatia, esse conhecimento do outro. Segundo Falcone (1999, p. 24), a empatia "caracteriza-se pela habilidade em compreender, de forma acurada, os sentimentos e a perspectiva da outra pessoa, bem como de transmitir entendimento de tal maneira que esta se sinta verdadeiramente compreendida e acolhida". Esse acolhimento do outro se faz presente no processo de inclusão, mostrando que o termo empatia significa "sentir com o outro e não pelo outro". Nesse processo de inclusão da criança com espetro autista, as imagens fornecem uma porta de entrada para compreender o funcionamento de sua mente, no qual, ser literal é um importante meio para a comunicação.

\footnotetext{
${ }^{1}$ Disponível em: http://www.reduziroestresse.com.br/2017/02/a-falta-de-empatia-e-superficialidade.html. Acesso em: 05/02/2019
} 
Figura 1: Tirinha do Armandinho sobre empatia
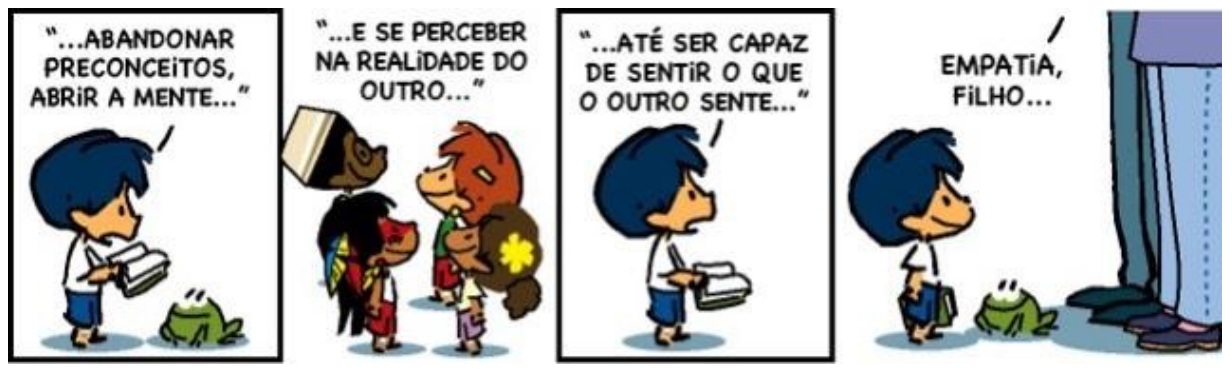

Fonte: Página reduzir o estresse.

Barroso (2006, p. 288) comenta que "o combate à exclusão na escola exige não só novos modos de regulação, mas também novas formas de organização". O desafio que se evidencia no contexto atual em relação ao combate à segregação e à exclusão é a criação de "espaços de recuperação da sociabilidade perdida". Será que por intermédio da música podemos possibilitar espaços de acontecimentos para crianças autistas? Como podemos recuperar a sociabilidade perdida começando pela Educação Infantil?

A inclusão tem como proposta uma mudança de paradigmas, ressalta uma pluralidade, faz vibrar o sistema educacional, pois não coloca os sujeitos em um modelo único de educação. No contexto educativo que abarca a inclusão, a criança constitui a sua identidade por meio das experiências coletivas reguladas juntamente ao professor.

Partindo dessa premissa, Mantoan (2003, p. 32) destaca que:

A inclusão é produto de uma educação plural, democrática e transgressora. Ela provoca uma crise escolar, ou melhor, uma crise de identidade institucional, que, por sua vez, abala a identidade dos professores e faz com que seja ressignificada a identidade do aluno. O aluno da escola inclusiva é outro sujeito, que não tem uma identidade fixada em modelos ideais, permanentes, essenciais.

Esse contexto necessita pensar sobre o papel de ensinar, levando em consideração a potencialidade, possibilidades das crianças, e não ficar apenas apertando a tecla dos seus déficits (SAMPAIO; SAMPAIO, 2009). O professor deve buscar um olhar em seu campo de atuação docente que reconheça e valorize o que pode ser feito pela criança. Nesse sentido, o professor precisa pensar em ser o 
regulador desse ambiente educativo, propiciando ouvir a voz de todas as crianças, cada tom conduzindo à sua melodia.

Estamos mergulhados em uma teia social, nos constituímos seres humanos na relação imbricada com o outro. Nesse sentido, Vigotski (2000, p. 33) entende a pessoa como "um agregado de relações sociais encarnadas num indivíduo". Pertencer ao mundo enquanto sujeito social condiz a organizar o meio, nossa maneira de viver. O desenvolvimento do homem consiste na relação do sujeito com a natureza, mas instiga nessa troca, um funcionamento psíquico complexo, emerge a consciência, o homem é social e cultural.

A teoria histórico-cultural tem como objetivo "[...] caracterizar os aspectos tipicamente humanos do comportamento e elaborar hipóteses de como essas características se formaram ao longo da história humana e de como se desenvolvem durante a vida de um indivíduo" (VIGOTSKI, 1998, p. 25). Este processo histórico do ser humano, em contato com o meio, repercute em uma maturação biológica, por meio dos acontecimentos da relação do homem e determinados contextos. Essa relação de trocas, mediada simbolicamente, presente em toda atividade humana, permite aos sujeitos agir sobre os elementos culturais, sociais e históricos. São os "instrumentos técnicos e sistemas de signos construídos historicamente, que fazem a mediação dos seres humanos entre si e deles com o mundo" (SAMPAIO; SAMPAIO, 2009, p. 58). Para Vigotski (1998), o desenvolvimento dos elementos que nos faz humanos acontece pela apropriação do homem desse emaranhado de experiências histórica e cultural.

Nessa constituição, temos como fio condutor as características eminentemente humanas que são o resultado de uma relação dialética do homem com o seu entorno sociocultural. Dessa maneira, a cultura é uma parte constituinte da natureza humana. Segundo Vigotski (1998, p. 40), "o caminho do objeto até a criança e desta até o objeto passa através de outra pessoa. Essa estrutura humana complexa é o produto de um processo de desenvolvimento profundamente enraizado nas ligações entre história individualmente social". O desenvolvimento do sujeito humano acontece por meio de uma fluência de interações sociais. 
desenvolvimento do psiquismo humano ocorre na relação com o outro, que amplia ou delimita, e atribui significados à realidade.

Enriquecer o contexto do espaço da Educação Infantil é importante, suscitar elementos para o desenvolvimento da criança, trazer a música para sua vida, não de maneira escolarizada, mas que entenda as singularidades de cada ser humano é fundamental. Às vezes, a rigidez e as formas mecânicas enraizadas no espaço da Educação Infantil tencionam e extraem as emoções do corpo, deixando-o fragmentado. Nesse sentido, Vigotski (2010, p. 213-214) relata que "não há emoção que seja por natureza independente do corpo, que não esteja ligada a ele". Compactua com a nossa ideia de educação na inteireza que respeita todos os elementos do corpo que nos constitui humanos, pois quando a educação retira a emoção, a ética, o respeito das práticas educativas, ela retira este corpo desse processo.

Nesse sentido, Pederiva e Gonçalves (2018, p. 315) mencionam que:

Educação musical na perspectiva histórico-cultural é: o processo de organização do espaço educativo intencionalmente estruturado em uma prática colaborativa, para trocas de experiências, em meio à vivências de percepções, compreensões, emoções, expressões e criações musicais que criam condições de possibilidade para o desenvolvimento da musicalidade de pessoas musicais históricoculturalmente constituídas, por meio de um processo educativo de aprofundamento consciente e da possibilidade de autorregulação do comportamento musical.

Por isso, ressaltamos a experiência com a música no espaço da Educação Infantil, por suas possibilidades, podendo constituir-nos seres humanos na sua plenitude, acontecer, quem sabe, vibrações no ser, com intensidade que permite retirar esse silêncio que pode bloquear toda a potência que a música pode deixar como vestígio na vida das crianças. A experiência para Larrosa (2017, p. 43), seria "o modo de habitar o mundo de um ser que existe, de um ser que não tem outro ser, outra essência, além da sua própria existência corporal, finita, encarnada, no tempo e no espaço, com outros". Habitar o mundo da inclusão seria se permitir um olhar mais apurado e afinado para os sons da vida em todos acordes. 
Nesse mundo permeado por uma teia sonora, buscamos neste artigo, por meio da teoria histórico-cultural e pelo olhar de outros autores, compreender as repercussões e vibrações da música no desenvolvimento sociocultural da criança com espectro autista na Educação Infantil. Olhamos também com empatia para a inclusão e para a educação musical imersa a este contexto.

A seguir, relataremos o "modo de habitar o mundo" de uma criança com espectro autista, suas singularidades, sua essência, nesse tempo e espaço. Após, teceremos experiências da nossa vida profissional na área de música com criança com autismo, refletindo com outros olhares pautados em autores que também dialogam sobre o tema abordado. Ao final, apresentamos as considerações finais e algumas recomendações.

\section{PEQUENOS GRANDES SERES HUMANOS}

Som, imagem, palavra... Nesse mundo repleto de signos constituídos em nosso percurso sócio-histórico, olhamos para a aprendizagem desde o nascimento da criança como fio condutor do desenvolvimento; é "um aspecto necessário e universal do processo de desenvolvimento das funções psicológicas culturalmente organizadas e especificamente humanas" (VIGOTSKI, 2007, p. 103). Dessa maneira, o aprender em um ambiente regulado pode oferecer possibilidades para repercutir no desenvolvimento das funções psicológicas superiores, como imaginação, linguagem, criação, entre outras.

$\mathrm{O}$ andamento dessas funções psicológicas superiores está subordinado às possibilidades do ambiente que constituem as experiências que acontecem na vida do sujeito, desde o seu nascimento. Essas experiências são movidas no corpo por meio das interações sociais e dos signos, esses sistemas simbólicos que fazem a conexão com as funções psicológicas superiores. Segundo Vigotski (1994), o signo articula a ação na consciência e dá origem às principais maneiras de condutas do ser humano. É um estímulo externo que ressoa para o interno do corpo.

Cabe ressaltar que as interações sociais na vida do ser humano implicam no seu desenvolvimento, porém existe o fator do refinamento dessas relações que a 
criança se envolve. Nesse sentido, Vigotski (2007) olha para o professor como sujeito que deve proporcionar condições de possibilidades para aprimorar as sensibilidades da criança para sentir, agir, pensar a sua relação com o mundo. De acordo com Vigotski (1994, p. 15):

Primeiramente o indivíduo realiza ações externas, que serão interpretadas pelas pessoas ao seu redor, de acordo com os significados culturalmente estabelecidos. A partir dessa interpretação, é que será possível para o indivíduo atribuir significados a suas próprias ações e desenvolver processos psicológicos internos que podem ser interpretados por ele próprio a partir dos mecanismos estabelecidos pelo grupo cultural e compreendidos por meio dos códigos compartilhados pelos membros desse grupo.

Nesse sentido:

Todas as funções no desenvolvimento da criança aparecem duas vezes: primeiro no nível social, e, depois, no nível individual; primeiro entre pessoas (interpsicológica), e, depois, no interior da criança (intrapsicologica) [...]. Todas as funções superiores originam-se das relações reais entre indivíduos humanos (VIGOTSKI, 1994, p. 75).

Cada criança é singular e busca à sua maneira de se relacionar com os outros e os signos que o seu entorno dispõe. Muitas vezes, existe a carência de uma ponte, de um conhecimento por parte do professor de conectar esses instrumentos simbólicos conforme as percepções de mundo de cada um. Quando falamos da criança com espectro do autismo, temos um quadro clínico de um transtorno que tem como característica déficit de interação social e comunicação, como também interesse e atividades repetitivas, de acordo com os critérios apresentados no Manual de Diagnóstico e Estatístico de Transtornos Mentais, $5^{\mathrm{a}}$ Edição (DSM-5)2. Além disso, existem alterações sensoriais que são características muito frequentes que geralmente não são notadas, pois existe a dificuldade de comunicação desses sujeitos. Há alguns exemplos de alterações sensoriais mencionadas pelo DSM-5:

\footnotetext{
2 O Manual diagnóstico e estatístico de transtornos mentais - DSM, da American Psychiatric Association é uma classificação de transtornos mentais e critérios relacionados com o intento de embasar diagnósticos que há 60 anos vem ganhando novas edições, sendo a última, $5^{a}$ edição, lançada em 2014. Sua classificação está interligada com a Classificação internacional de doenças - CID, da Organização Mundial da Saúde, que é o sistema oficial utilizado nos Estados Unidos
} 
"fascínio visual por luzes ou objetos que rodam, resposta adversa a sons ou texturas específicas, cheiro ou toque excessivos de objetos, aparente indiferença a dor, calor ou frio" (POSAR; VISCONTI, 2018, p. 343).

A criança com espectro autista tem uma sensibilidade diferente de perceber as nuances do mundo. Uma imagem abre dimensões incríveis, redes de ligações das mais variadas possíveis; um som desconfortável é sentido por baixo da pele com toda intensidade; um sabor desagradável suscita um gosto que gruda com toda sua força na sua língua; um assunto de seu interesse torna-se uma paixão grande que perdura em sua vida por longo tempo. Ao relatar sobre a educação de crianças com deficiência, Vigotski (1997) discorre que é crucial a interação estabelecida com os outros, pois é por meio do contexto sociocultural que a criança se encontra imersa na teia de possibilidades: emerge assim a superação da condição de deficiência. O autor acreditava na potencialidade do cérebro, sua plasticidade, e capacidade que o ser humano converge nas adversidades de se adaptar e superar as dificuldades que não podem impedir o seu ser e estar no mundo.

É importante relatar que "[...] o que decide o destino da pessoa, em última instância, não é o defeito em si mesmo e sim as consequências sociais, sua realização psicossocial" (VIGOTSKI, 1997, p. 19). O contexto da Educação Infantil tem como possibilidade buscar a ligação desses fios confluentes que aparecem nesses espaços, enfatizar o respeito às diferenças, como um objetivo de enriquecer as pluralidades da ação educativa dos professores e de todas as crianças.

Como podemos trazer visibilidade para essas crianças? Criar espaços de acontecimentos? Fica nítido o quanto é nocivo para a criança com deficiência ser excluída culturalmente, através do obstáculo do estranhamento, do diferente. Essas crianças não conseguem exercitar as atividades de nossa cultura (SAMPAIO; SAMPAIO, 2009). Este fator pode criar lacunas significativas no seu desenvolvimento, pois quando ressaltamos Vigotski, é para lembrar que as ações educativas geram possibilidades, mas, sem afeto, ética e respeito às singularidades, as percepções de mundo de cada um não acontecem e, assim, podemos criar elementos danosos que marcam a sua existência. 
A partir da revisão de literatura realizada, acreditamos que é necessário trazer visibilidade, fazer ressoar a sua própria melodia, reconhecer sua identidade, sua força dentro desse pequeno grande ser humano. É interessante criar espaços para conceber a inclusão na vida do indivíduo, ampliar as experiências, um alargamento de uma realidade mais acessível, no caso desse artigo por intermédio da música. Buscar o cognitivo, os fatores culturais e sociais como propulsores da empatia, inclusão e humanização.

\section{SENSÍVEL SER VIBRANTE!}

Consciência do mundo, a criança com espectro autista sente esse mundo dentro do seu próprio espectro que orbita em sentido diferente, porém não inibe de permear por caminhos sonoros, pela música na sua intensidade, com seus timbres, alturas, duração, melodias e harmonias que possibilitam que a criança vibre em ressonância com esses saberes. Nesse sentido:

A música, como sendo um meio de comunicação não verbal é uma linguagem que facilita a expressão de sentimentos e dá uma nova alternativa de comunicação, possibilitando uma maior descoberta de quem a prática e interação com seus pares. Tais fatores são de grande importância para a criança com autismo, pois isto a conecta com o ambiente e cria um meio que possibilita a vazão de suas pulsões (PENDEZA; SOUZA, 2015, p. 10).

A experiência com música pulsa de uma maneira que necessita atenção às singularidades de cada criança. A criança com espectro autista pode olhar para os fenômenos sonoros com uma carga de emoção, comunicação, interagindo com outras crianças nesse processo. Mas, existem relações com o espectro autista que precisam de maior clareza antes de apresentar este universo sonoro. Uma delas encontra-se na comunicação. A criança com espectro autista utiliza outras estratégias de comunicação. Dependendo da singularidade de cada criança com autismo e seu grau, necessitam de materiais diferenciados durante a aula de música, recursos com imagens, texturas, formas, não somente a música pela música. Segundo Fróis (2000, pp. 112/113) 
Todos nós sabemos, a partir da experiência de ouvir música, como a música dá origem a diferentes tipos de emoções. A música tem a capacidade de estimular diferentes emoções, fazendo parecer como se estas emoções pertencessem à própria música, embora, na realidade, o movimento ou fluxo da música provoque estas respostas emocionais.

A escuta musical ativa é importante para despertar a perspectiva sensorial na criança com espetro autista. Escutar diversos timbres de instrumentos musicais tem o papel de ampliar o repertório sonoro, experimentando assim, novas sensações estéticas e adquirindo novos conhecimentos. Abaixo temos a família dos metais que pertencem a orquestra. Nesse sentido a escuta de cada instrumento musical sensibilizando para aspectos condizentes ao seu timbre (característica singular de cada som), altura (sons graves e agudos) é a primeira etapa proposta. Trazer vídeos com os músicos tocando cada instrumento musical é uma opção interessante que visa um olhar mais apurado para cada timbre diferenciado. Nesse sentido apresenta-se a seguir um exemplo3:

Figura 2: Quatro instrumentos da Família dos Metais na Orquestra (trompete, trompa, trombone de vara e tuba)

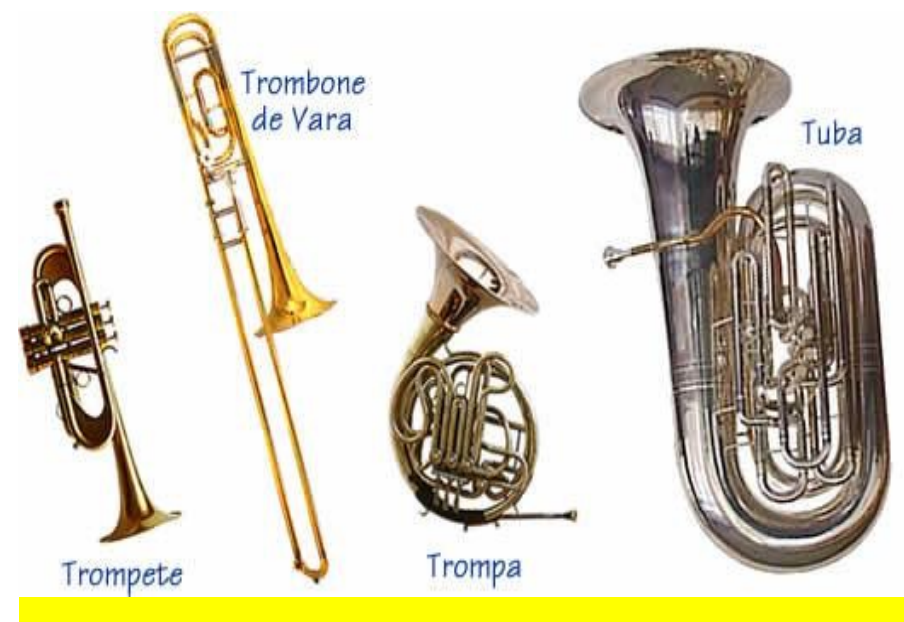

Fonte: Página Fnaomyking.wordpress

\footnotetext{
3 Disponível em: https://www.google.com/url?sa=i\&source=images\&cd=\&ved=2ahUKEwip-

YHW6t7fAhVBE5AKHfkCAFMQjhx6BAgBEAM\&url=https\%3A\%2F\%2Fnaomyking.wordpress.com\%2Finstrument os-de-sopro\%2F\&psig=AOvVaw2RKqz5prykFxhDQENvltst\&ust=1547059169357137. Acesso em: 20/02/2019
} 
Figura 3: Salvador Dali - Obra: Elefantes Musicais, 1944

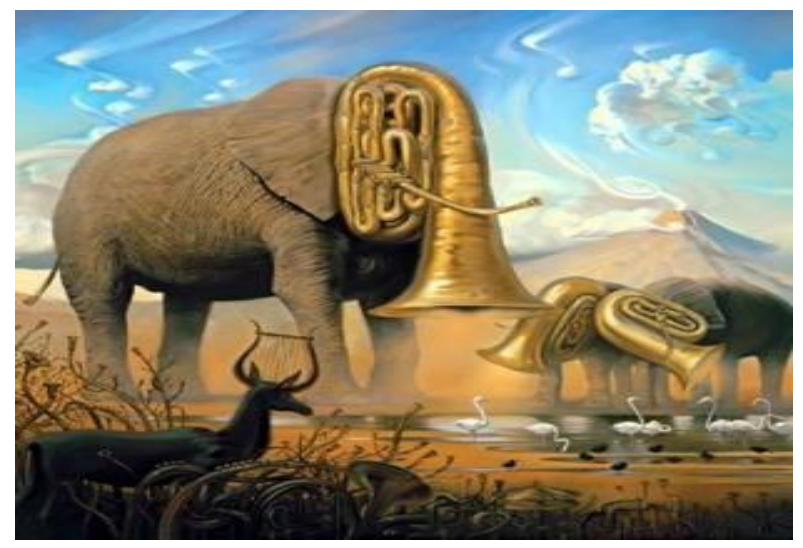

Fonte: Página Pinterest.

Após a escuta dos timbres dos instrumentos pertencentes a figura (2), podemos conectar associações com outras formas de arte como, por exemplo, a pintura de Salvador Dali, figura $(3)^{4}$, explorando o elefante e a tuba numa dinâmica de altura, comparações desses sons, que podem abrir novos universos de conhecimentos musicais criando signos novos no processo intrapsíquico na criança com espectro autista. A associação permite ir além da música pela música, trazer animais como o elefante com curiosidades sobre ele, seu som, etc. Segundo Godinho e Brito (2010, p. 107),

Os animais provocam um grande interesse nas crianças e não é por acaso que muitas histórias infantis são fábulas. Através das histórias, os animais assumem diversas características humanas, projetandose neles muito daquilo que somos ou que gostaríamos de ser. Nos desenhos livres, por outro lado, um dos temas mais escolhidos pelas crianças são os animais, logo a seguir à figura humana e à casa.

Enfatizando a perspectiva de Godinho e Brito acerca do fascínio que as crianças têm pela temática animal, Constança, (s/d, p.11) afirma:

A criança procura dentro de si as expressões da natureza que naturalmente a encaminha e lhe desperta os sentidos. $E$ a vida dos animais, como se sua própria fosse, dá-lhe um campo permanentemente renovado de grandes descobertas. Crianças e

\footnotetext{
4 Disponível em: https://br.pinterest.com/pin/736901557749194529/?lp=true. Acesso em: 23/03/2019.
} 
animais aproximam-se. Dir-se-ia que, por imperativo de um verdadeiro milagre, se estabelece entre eles um mútuo entendimento.

A criança revela fascínio pela descoberta, por desbravar o mundo que a permeia, como funciona. Os animais é uma potência temática para conectar diversas áreas do saber desde a área do conhecimento do mundo, expressões (musical, dramática, motora, visual), língua portuguesa, matemática e ainda a área da formação pessoal e social. O papel dos educadores é de proporcionar elementos que instiguem essas descobertas de forma espontânea e independente, apresentado diversos materiais criativos, organizando os espaços, preparando um ambiente rico para criança com espetro autista.

Para aprofundar a temática elefante, proposta anteriormente na figura (3), podemos apresentar uma atividade de escuta musical ativa com a obra Carnaval dos Animais do compositor Camile Saint- Saëns com música $O$ Elefante, que é apenas de cunho instrumental. "Carl Orff defendia que os primeiros contatos com a música instrumental se deviam fazer cedo, devendo a sua aprendizagem elementar ser fácil e imediata" (AMADO, 1999, pp. 45/46). Nela sentimos o andar pesado, lento, do elefante carregado de toda sensação possível de vibrar no corpo e na consciência da criança com espectro autista. O "Carnaval dos Animais" é constituído por catorze peças musicais, tendo um caráter imitativo, descritivo ou representativo de diversos animais. "Esta obra funcionou também, na época em que foi composta, como uma sátira social a diferentes pessoas e estilos de pessoas dessa época" (GODINHO; BRITO, 2010, p.108).

O tema do elefante é executado neste exemplo ${ }^{5}$, por piano e contrabaixo acústico, instrumento da família das cordas de som grave, que induz um conforto devido à sensibilidade auditiva do autista como mencionada anteriormente. Esta obra apenas instrumental mostra que também é possível transmitir sensações e informações aos ouvintes sem texto. A música instrumental abre um leque de possibilidades, esta temática do Elefante da Obra Carnaval dos Animais é possível

\footnotetext{
${ }^{5}$ Camile Saint- Saëns/ Música O Elefante. Acesso: https://www.youtube.com/watch? $\mathrm{v}=\mathrm{f} 1 \mathrm{nVDoCnsNk}$
} 
de dramatização com mímicas, combinando a expressão corporal com os animais e o ritmo da música que ouviram. Esses são apenas alguns exemplos de ideias de atividades para propiciar espaços de acontecimentos musicais com a criança com espectro autista.

A seguir apresentamos um quadro para elucidar algumas características marcantes do espectro autista, que possibilitam pensar em espaços de acontecimentos com a Educação Musical na Educação Infantil.

\section{Quadro 1: Manifestações do Autismo}

\begin{tabular}{|c|c|c|c|}
\hline $\begin{array}{l}\text { Problemas } \\
\text { comunicativos e } \\
\text { linguísticos }\end{array}$ & $\begin{array}{l}\text { Problemas nos } \\
\text { relacionamentos } \\
\text { sociais }\end{array}$ & $\begin{array}{c}\text { Padrões restritos de } \\
\text { interesse }\end{array}$ & $\begin{array}{l}\text { Problemas com } \\
\text { aprendizagem }\end{array}$ \\
\hline $\begin{array}{l}\text { Atraso/desvios na } \\
\text { aquisição da fala. }\end{array}$ & Isolamento/Indiferença. & $\begin{array}{l}\text { Foco e apego em } \\
\text { detalhes. }\end{array}$ & $\begin{array}{l}\text { Dificuldades com as } \\
\text { vias tradicionais de } \\
\text { ensino. }\end{array}$ \\
\hline $\begin{array}{l}\text { Ecolalia/fala auto } \\
\text { regulatória. }\end{array}$ & $\begin{array}{l}\text { Falhas na atenção } \\
\text { compartilhada e } \\
\text { reciprocidade. }\end{array}$ & $\begin{array}{l}\text { Interesses restritos e } \\
\text { pontuais. }\end{array}$ & $\begin{array}{l}\text { P r o b l e m a s } \\
\text { psicomotores / } \\
\text { desenvolvimento } \\
\text { desnivelado. }\end{array}$ \\
\hline $\begin{array}{l}\text { Dificuldades com troca } \\
\text { de turnos dialógicos. }\end{array}$ & $\begin{array}{l}\text { Dificuldades com troca } \\
\text { de turnos lúdicos e } \\
\text { interpessoais. }\end{array}$ & $\begin{array}{l}\text { Apego a rotinas / } \\
\text { mesmices / objetos. }\end{array}$ & $\begin{array}{l}\text { Habilidades viso } \\
\text { espaciais. }\end{array}$ \\
\hline $\begin{array}{l}\text { Ausência de fala e de } \\
\text { m e c a n i s m o s } \\
\text { compensatórios. }\end{array}$ & $\begin{array}{l}\text { Dificuldades com o uso } \\
\text { da teoria da mente. }\end{array}$ & $\begin{array}{l}\mathrm{Prob} \text { l e m a s com } \\
\text { mudanças na rotina. }\end{array}$ & $\begin{array}{l}\text { Busca por referências } \\
\text { visuais. }\end{array}$ \\
\hline $\begin{array}{l}\text { Dificuldades com uso } \\
\text { de sinais não verbais } \\
\text { na comunicação. }\end{array}$ & $\begin{array}{l}\text { Uso não funcional de } \\
\text { regras e habilidades } \\
\text { sociais. }\end{array}$ & $\begin{array}{l}\text { B a ixo uso d a } \\
\text { criatividade, apego a } \\
\text { habilidades de } \\
\text { memória. }\end{array}$ & $\begin{array}{l}\text { Necessidade de ajuda } \\
\text { fís ic a para } \\
\text { complementação de } \\
\text { tarefas. }\end{array}$ \\
\hline $\begin{array}{l}\mathrm{P} r \text { o b l e } \mathrm{m} \text { a } \mathrm{s} \\
\text { pragmáticos. }\end{array}$ & $\begin{array}{l}\text { Podem acontecer } \\
\text { episódios de auto } \\
\text { agressividade e/ou } \\
\text { agressividade para com } \\
\text { as pessoas. }\end{array}$ & $\begin{array}{l}\text { Dificuldades com uso } \\
\text { d e o b j e tos } \\
\text { brinquedos. }\end{array}$ & $\begin{array}{l}\text { Desvios atencionais e } \\
\text { nas funções executivas. }\end{array}$ \\
\hline Problemas semânticos. & $\begin{array}{l}\text { Dificuldades com a } \\
\text { noção de perigo. }\end{array}$ & $\begin{array}{l}\text { Movimentos repetitivos } \\
\text { e estereotipados. }\end{array}$ & $\begin{array}{l}\text { Atraso / desvios nas } \\
\text { aquisições escolares. }\end{array}$ \\
\hline
\end{tabular}

Fonte: Fonseca e Ciola (2016).

O quadro não pode ser utilizado como modelo, nem ser entendido como a única possibilidade sobre trabalho com crianças autistas, pois cada criança é singular, entretanto, existe um conjunto de fatores que necessitam de uma atenção diferenciada que dependerá do grau do autismo, envolvimento da família, professores, equipe gestora, o espaço da Educação Infantil frente à inclusão e à 
música. Nesse sentido, a música pode ser um grande alicerce, não apenas para a criança com autismo, mas para as crianças neurotípicas também. Segundo Gonçalves (2017, p. 245):

A unidade dialética educação-música, enquanto educação do desenvolvimento da musicalidade humana, cristalizada na atividade musical educativa que pode se dar em qualquer ambiente social, na teoria histórico-cultural de Vigotski, engloba as problemáticas que estão imbuídas na arte da música: experiência musical, vivência musical, criação musical, imaginação musical, combinação musical, reprodução musical, emoção musical e sentimento estético-musical, catarse musical etc.

Existe uma coesão da música com a experiência estética, uma experiência que precisa da entrega do corpo por inteiro. Por isso, regular o espaço para todas as crianças é um fator essencial para enaltecer esses momentos com a música no plano intrapsíquico. Explorando elementos diversos e complexos mencionados por Vigotski como imaginação, por exemplo, a criança com espectro autista devido ao seu apego à memorização (Quadro 1), leva as palavras no sentido literal, por isso histórias e músicas que utilizem da metáfora tornam-se uma dificuldade. Então, a escolha do repertório musical que contenha texto precisa de uma acuidade na sua seleção.

Ecolalia é outro exemplo para o movimento de repetição (Quadro 1). Kanner, pioneiro na discussão sobre autismo, afirma que a ecolalia é "repetição de frases completas" (KANNER, 1997, p. 242). Shapiro e Lucy (1978, p. 373), por sua vez, afirmam que a ecolalia em crianças com espectro autista corresponde a "uma repetição exata uma parte do enunciado modelo". Apesar do termo ser caracterizado para o aspecto relacionado a fala, podemos olhar com sensibilidade para a música. Pensando nessa estrutura de repetição, sugerimos a música Dança dos sete saltos (Siebensprung), música tradicional da Alemanha (DEUTSCHE GESELLSCHAFT (Seção Brasil). Tanzbeschreibung: Siebensprung. Gramado, RS, 1988). Este repertório traz uma sensação de conforto, pois sua estrutura de repetição não possui elemento surpresa que pode causar uma sobrecarga de estímulos e desestabilizar a criança com espectro autista. Abaixo, segue a sugestão de uma proposta, uma ação 
musical pensando em criar espaços de apreciação musical que pense na criança com espectro autista.

A atividade consiste em uma escuta consciente e não apenas ouvir por ouvir sem nenhum aprendizado. França e Swanwick (2002, p.13) afirmam que: "ouvir uma grande variedade de música alimenta o repertório de possibilidades criativas sobre as quais os alunos podem agir criativamente, transformando, reconstruindo e reintegrando ideias em novas formas e significados". (FRANÇA; SWANWICK 2002, p. 13). Cabe ao professor a melhor maneira de propiciar a diversidade musical que temos à nossa disposição, respeitando as singularidades de cada educando.

Ação musical6: O primeiro objetivo é conhecer as características da música selecionada para a atividade. Dança popular: Dança dos sete saltos (Siebensprung), que se difundiu para além das fronteiras alemãs (Dos Pirineus - cordilheira entre França e Espanha - até região da Escandinávia - norte da Europa). A história da obra se relaciona ao cortejo, inauguração de igrejas, casamentos e agradecimentos pela colheita. Música associada ao movimento corporal e palmas. Para realizar a Dança dos Sete Saltos é necessário saber que ela consiste em movimentos sequenciais, realizados com o corpo e de cunho cumulativo, que se repetem no decorrer da obra. Em roda, são realizados os seguintes movimentos que se repetem numa parte específica da obra musical: na primeira parte a roda gira e são repercutidas palmas na parte rítmica da música. Após as palmas, a roda vai girar para o sentido inverso. Em seguida, em uma parte específica da obra, temos o primeiro movimento cumulativo que é colocar o joelho direito no chão. Depois, volta todo o movimento de roda, como já descrito anteriormente com as palmas e a roda girando. Repete o primeiro movimento em uma parte especifica da música e como segundo movimento, vem o joelho esquerdo no chão. $O$ processo se repete novamente lembrando de repetir o primeiro e segundo movimento já descritos. $O$ terceiro movimento é a mão direita no chão, o quarto é a mão esquerda no chão, o quinto cotovelo direito no chão, o sexto cotovelo esquerdo no chão e o sétimo e último movimento, cabeça no chão. Faixa etária: Creches e prés (três a seis anos).

\footnotetext{
6 MADALOZZO, Vivian A; MADAZZOLO Tiago. Oficina: Planejamento e prática musical na educação infantil: o jogo musical, a audição ativa e o fazer musical lúdico. XVI Encontro Regional ABEM. Blumenau, 2014 (Atividade e áudio).
} 
Sugerimos, também, utilizar nesta música, as clavas instrumento musical de fácil manuseio para marcação do pulso da música, tocar o ritmo das palmas. Além de possibilitar explorar diversas maneiras de tocar o instrumento musical com as crianças acompanhando a música. Fazendo cada movimento com as clavas na parte que sugere o movimento corporal cumulativo.

O saber da experiência faz acontecer, tombar o corpo inerte que precisa estar aberto a novas percepções mundo, um espaço para habitar (LARRROSA, 2017). Essa abertura depende de um corpo sensível que terá marcas menos ou mais intensas do exterior, muitas vezes de rupturas, essas quebras, curto-circuito que tira do estado de equilíbrio com meio, por meio da música esse corpo é jogado na descoberta da sua própria existência, encontra uma significação interna. Segundo Larrosa (2017, p.18), “a experiência é o que nos passa, o que nos acontece, o que nos toca. Não o que se passa, não o que acontece, ou o que toca. A cada dia se passam muitas coisas, porém ao mesmo tempo, quase nada nos acontece". Para a experiência acontecer "requer um gesto de interrupção" (LARROSA. 2017, p. 45). Cultivar as delicadezas, abrir os ouvidos para os sons do mundo, cultivar a arte do encontro, esses espaços de acontecimentos (LARROSA, 2017). A experiência possibilita que algo nos toque, por isso a importância de proporcionar atividades musicais que pensem na criança com espectro autista.

Segundo Vigotski (2003, p. 76), "acima de tudo, educar significa estabelecer novas reações, elaborar novas formas de conduta". De acordo com o autor:

Toda educação tem inevitavelmente um caráter social [...] o único educador capaz de formar novas reações no organismo é a própria experiência. Para o organismo, só é real o vínculo que ocorreu em sua experiência pessoal. Por isso, a experiência pessoal do educando transforma-se na principal base do trabalho pedagógico. Não é possível exercer uma influência direta e produzir mudanças em um organismo alheio, só é possível educar a si mesmo, isto é, modificar as reações inatas através da própria experiência (VIGOTSKI, 2003, p. 75).

A experiência cria ligações pautadas na realidade sentida pela criança. Ela vibra e faz a criança pensar (LARROSA, 2017). No caso de a criança com espectro autista perceber os estímulos à sua volta, sem que eles se tornem uma experiência 
negativa na sua psique humana, para isso, regular o espaço com a plena consciência de um processo de inclusão que não seja invasivo e sim, sensível ao ser humano e as suas singularidades.

Podemos pensar que muitas vezes focamos na deficiência e não enxergamos outras possibilidades de cores e sons sendo que "a deficiência deixa de ser o foco e o que entra em questão são as formas de educar, que garantirão ao indivíduo a conquista do respeito social desde cedo" (GIVIGI, 2007, p. 36).

Nesse sentido, o desafio é que crianças com espectro autista se apropriem dos signos culturais e sociais orientando-se como possibilidade de comunicação, socialização e relação no mundo e seus aspectos culturais. Pensar na continuidade de segmentos primordiais para a constituição docente é o elo que liga uma educação que fomente caminhos que olhem uma mudança continua do ser humano, o qual é forjado em situações de experiências e na relação com o outro nesse processo.

Nóvoa (1992, p. 15) comenta que "práticas de formação que tomem como referência as dimensões coletivas contribuem para a emancipação profissional e para a consolidação de uma profissão que é autônoma na produção dos seus saberes e dos seus valores". Um dos caminhos para a inclusão é valorizar o trabalho docente, nesse sentido, possibilitando que os professores em uma dimensão coletiva teçam compreensões dos contextos histórico-culturais e organizacional que fazem parte da sua ação docente. Para Nóvoa (2004, p. 16),

[...] o formador [forme-se] a si próprio, através de uma reflexão sobre os seus percursos pessoais e profissionais (autoformação); o formador [forme-se] na relação com os outros, numa aprendizagem conjunta que faz apelo à consciência, aos sentimentos e às emoções (heteroformação); o formador [forme-se] através das coisas (dos saberes, das técnicas, das culturas, das artes, das tecnologias) e da sua compreensão crítica (ecoformação).

Este caminho de emancipação constituindo na pluralidade da diversidade podem transformar lógicas de ensino, tanto no âmbito do espaço da educação infantil como a elaboração de suas políticas educacionais. Pensar em inclusão é, também, pensar no regulador do ambiente da Educação Infantil, nesse espaço como 
lugar de transformação, no qual o professor assume um papel importante e refletir sobre essas concepções e condições é o alicerce para a constituição de novos saberes e práticas.

\section{CONSIDERAÇÕES FINAIS}

Possibilidades para uma educação mais inclusiva é um desafio constante. A experiência com a música no contexto educativo pode criar espaços para acontecimentos, movimentos que organizam a vida musical em um ambiente educativo transformador, surgindo assim, novos comportamentos na vida da criança (VIGOTSKI, 1995).

A criança com espectro autista possui dificuldade na socialização com outros pares, como apresentado no Quadro 1. Por isso, a educação musical que possibilita um coletivo de vozes se torna uma influência direta nas mudanças de comportamento de todas as crianças que participam das vivências musicais. Somos seres essencialmente sociais, a experiência é essencial para humanizar, a cultura e sua socialização são a base para um novo ser humano e a música se insere neste contexto plural da Arte.

A história e a cultura nos constituem como seres humanos que somos (VIGOTSKI, 1995). Não queremos outro enigma como "o enigma de Kaspar Hauser"7 que apenas depois de passado um período de tempo, começou o processo de socialização. No espaço da Educação Infantil existe um mundo de possibilidades com a música, com a Arte, cria fios de conexões entre o lá e o aqui. Esse paralelo é possível se conhecermos a situação e criar redes para regular os estímulos respeitando o tempo, e as características individuais de cada criança. Socialização é a base da mudança, experiências da transformação humana.

Ampliar o universo pessoal por meio da música possibilita contemplar na vida do ser humano um alagamento de experiências alheias e vislumbrar assim, passos significativos para a inclusão, pois na própria realidade ela vivencia sonoridades que

\footnotetext{
7 Filme/Sinopse: Kaspar Hauser encontra-se perdido em relação ao mundo que o permeia. Não consegue falar ou se locomover quando é finalmente encontrado nos anos 1820. Seu enigma que norteia o enredo é o fato de passar a vida toda trancado, sendo espancado e sem qualquer convívio com outros seres humanos. As pessoas que o encontram tentam civilizá-lo de diversas maneiras.
} 
serão incorporadas e findadas em processos psíquicos mais complexos que superam a simples experimentação. Infelizmente, conforme constata Orrú (2009), a realidade da educação especial no Brasil ainda enaltece mecanismos históricos de exclusão com seu direcionamento de cunho pedagógico organicista.

No embate gerado pela atual política de inclusão, um aspecto fundamental é o de que a educação especial, em sua trajetória histórica, apresenta-nos uma concepção centrada no déficit e/ou doença no que diz respeito à pessoa com deficiência, desmerecendo a importância dos aspectos socioculturais próprios da condição humana (ORRÚ, 2009, p. 50).

O contexto da educação infantil pode oportunizar espaços e socialização, contatos sociais que oportunizam uma constituição humana mais global. Segundo Campolina e Martínez (2011, p. 45), “os professores estão tão comprometidos com o mito das escolas que, frequentemente, não se permitem pensar seriamente sobre a natureza das escolas ou sobre alternativas para elas". O que acaba em um quadro crônico de rotinas mecânicas, que não sensibilizam a singularidade de cada criança. Podemos começar com uma ação de "perturbar o som do silêncio", com a música temos uma maneira de comunicação que pode ser o alicerce de práticas educativas mais inclusivas. Superando dificuldades de situações de inclusão e ineficiência do sistema escolar para regular espaços com arte que transbordem em transformações e ações mais humanizadas.

O artigo apresentado foi de cunho teórico a partir de um recorte de algumas leituras e visão de mundo na tentativa de instigar possíveis reflexões da música na vida da criança com espectro autista. Não teve uma revisão exaustiva de pesquisas empíricas realizadas, procuramos de maneira breve elucidar abordagens sobre inclusão, espectro autista e música. A proposta prática foi brevemente desenvolvida como forma de ilustrar. Com isso, podemos pensar em possibilidades de pensar pesquisas futuras para discutir e investigar aspectos específicos.

As interações em sala de aula partem de uma multiplicidade de signos culturais. A música possibilita "quebrar" alguns paradigmas consolidados pela falta de diálogos e carência em repertórios ricos que podem agregar uma nova perspectiva educacional na aprendizagem de crianças com espectro autista. A 
inclusão pela música pode ser o ponto de partida, mas tudo começa sempre na vontade humana, no compartilhar, para que aconteça pequenas, mas significativas mudanças no corpo de cada criança, inclusive nas invisíveis que, talvez quem sabe, daqui a algum tempo, não sejam mais.

\section{REFERÊNCIAS}

AMADO, M. (1999). O Prazer de Ouvir Música - sugestões pedagógicas de audições para crianças. Lisboa: Editorial Caminho.

AMERICAN PSYCHIATRIC ASSOCIATION. Manual diagnóstico e estatístico de transtornos mentais: DSM-5. 5.ed. Porto Alegre: Artmed, 2014.

BARROSO, J. Incluir sim, mas onde? Para uma reconceituação sociocomunitária da escola pública. In: RODRIGUES, D. (Org). Inclusão e Educação: Doze olhares sobre educação inclusiva. São Paulo: Summus Editorial, 2006.

CAMPOLINA, L. O.; MARTÍNEZ, A. M. A Escola em sua Dimensão Reprodutiva: Possibilidades e Limites de Inovação na Educação. In: TUNES, E. (org.) Sem Escola, Sem Documento. Rio de Janeiro: E-papers, 2011.

DUSSEL, E. Filosofía de la Liberación. 7. ed. México: Primero, 2001.

FALCONE, E. M. O. A avaliação de um programa de treinamento da empatia com universitários. Revista Brasileira de Terapia Comportamental e Cognitiva, São Paulo, v. 1, n. 1, p. 23-32, jun. 1999.

FRANÇA, C. C; SWANWICK, K. Composição, Apreciação e Performance na Educação Musical: teoria, pesquisa e pratica. In: Em Pauta - Revista de Pós-Graduação em Música da UFRGS - Porto Alegre, v. 13, n. 21, p. 13, dez. 2002.

FONSECA, M. E. G.; CIOLA, J. C. B. Vejo e Aprendo: Fundamentos do Programa TEACCH - o ensino estruturado para pessoas com autismo. Ribeirão Preto: Book Toy, 2016.

FRÓIS, J. (coord), (2000). Educação estética e artística. Lisboa: Fundação Calouste Gulbenkian.

GIVIGI, R. C. N. Tecendo redes, pescando ideias: (re)significando a inclusão nas práticas educativas da escola. 2007. 233f. Tese (Doutorado em Educação) - Universidade Federal do Espírito Santo, Centro de Educação. 2007.

GODINHO, J.; BRITO, M. (2010). As artes no Jardim de Infância - Textos de apoio para Educadores de Infância. Lisboa: Ministério da Educação.

GONÇALVES, A. C. A. B. Educação musical na perspectiva histórico-cultural de Vigotski: a unidade educação-música. 2017. xiii, 277 f., il. Tese (Doutorado em Educação) Universidade de Brasília, Brasília, 2017.

KANNER, L. Os distúrbios artísticos do contato afetivo. In.: ROCHA, Paulina Schmidtbauer (Org.). Autismos. São Paulo: Escuta. 1997.

LARROSA, J. Tremores: escritos sobre experiência. Belo Horizonte: Autêntica, 2017. 
MANTOAN, M, T, E. Inclusão Escolar: O que é? Por quê? Como fazer? São Paulo, Brasil: Moderna, 2003.

NÓVOA, A. Prefácio. In: JOSSO, M.C. (Ed.). Experiências de vida e formação. São Paulo: Cortez, 2004. p. 11 - 34.

NÓVOA, A. Formação de professores e profissão docente. In: NÓVOA, A. Os professores e sua formação. Lisboa - Portugal: Dom Quixote, 1992.

ORRÚ, S. E. Autismo, linguagem e educação: interação social no Cotidiano escolar. Rio de Janeiro: Wak Editora, 2009.

PEDERIVA, P. L. M.; GONÇALVES, A. C. A. B. Educação musical na perspectiva históricocultural: uma didática para o desenvolvimento da musicalidade. Revista: de Didática e Psicopedagogia |Uberlândia, MG. v.2. n. 2, 2018. p. 314-338.

PENDEZA, D. P.; SOUZA, T. M. F. A educação musical como instrumento psicopedagógico no atendimento a crianças com transtorno do espectro do Autismo. Revista Pesquisa, v.10, n.13, 2015, p. 156-170,

POSAR, A.; VISCONTI, P. Sensory abnormalities in children with autism spectrum disorder. Jornal Pediatria (Rio Janeiro). 2018; 94:342-50.

SAMPAIO, C. T; SAMPAIO, S. M. R. Refletindo sobre a educação inclusiva. In: Educação inclusiva: o professor mediando para a vida. Salvador: EDUFBA, 2009, p. $55-73$

SHAPIRO, T; LUCY, P. Echoing in autistic children: achronometric study of semantic processing. Journal of Child Psyholoy and Psychiatry. v. 19, out. 1978.

VYGOTSKY, L. S. A formação social da mente: o desenvolvimento dos processos psicológicos superiores. São Paulo: Martins Fontes, 1994/1998.

. Obras escogidas, V. 5. Fundamentos de defectologia. Madrid: Ed. Visor, 1997.

Obras escogidas IV. Psicologia infantil. Madrid: Ed. VISOR, 1995. de A. A Puzirei.

Manuscrito de 1929. Educação \& Sociedade, XXI (71), 23-44, jul. 2000. Tradução A., 2010.

Teoría de las emociones: estudio histórico-psicológico. Madrid: Editora Akal, S.

A formação social da mente. 7. ed. São Paulo: Martins Fontes, 2007

VYGOTSKY, L. S. La Psicologia Pedagógica (Edição comentada). Porto Alegre: ARTMED, Editorial Progreso, 2003. 